\title{
Testing Whole Building LCA: Research and Practice
}

\author{
Environmental Life Cycle Assessment (LCA) can be used to evaluate the \\ environmental impacts of a building resulting from manufacturing, construction, \\ operation and maintenance and the end of life demolition and disposal/re-use. \\ Tracking impacts such as greenhouse gas emissions and smog formation, LCA \\ can enable comparison of building proposals testing options of material use, \\ system selection and system performance.
}

Green building programs such as the U.S. Green Building Council's LEED V4 rating system (USGBC, 2014), the Living Building Challenge (ILFI, 2014) and the International Green Construction Code (IgCC) (ICC, 2012) have included whole building LCA as a method to evaluate the environmental impact of buildings. These programs provide varying levels of guidance on how to perform the requested LCA and all require significant interpretation in order to implement. While the number and type of LCA tools designed for architects and engineers to use in developing whole building LCAs are expanding, these tools have different strengths and weaknesses and users have few appropriate resources for evaluating which tools to use and how best to use them when conducting whole building LCAs.

An industry-academic collaborative research effort, the Carbon Leadership Forum (CLF), founded in 2009 and hosted by the University of Washington includes a diverse group of professionals (architects, engineers, contractors, material manufacturers, LCA practitioners and industry trade organizations) advancing research to support the use of LCA data and methods within design and construction practice. One of the CLF's current research projects is to conduct whole building LCA case studies of buildings conducted in collaboration with design and/or construction teams to test the application of the whole building LCA credits in LEED V4 and the IgCC. This research funds graduate and undergraduate architecture students to be trained in LCA practices and is conducted in collaboration with the design teams.

Three LCA case studies have been completed (as represented in figure 1), each of different project types and each in collaboration with different project representatives. The research tested different LCA tools and evaluated design alternatives in an attempt to quantify a reduction to the building's overall environmental impact. The methods and preliminary results of these LCAs is presented here along with commentary regarding the potential and challenges of integrating whole building LCA and green building rating systems.

The focus of all three studies has been identifying methods to improve the environmental performance of the structural system in unique ways: case study one compared the use of different structural materials, case study two looked to optimize the concrete structure
KATHRINA SIMONEN

University of Washington 
1: Office Structure
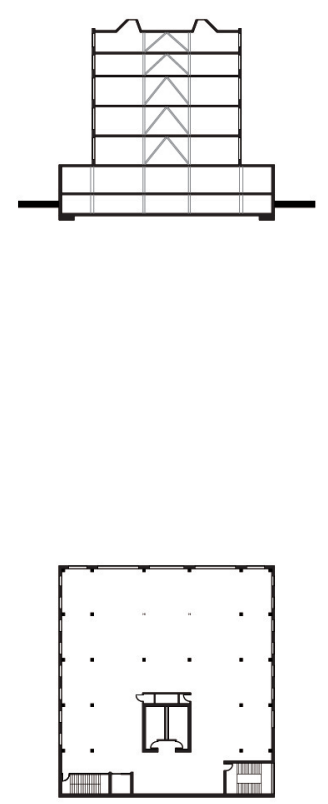

1

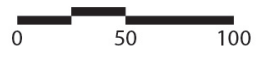

2: Tower Optimization
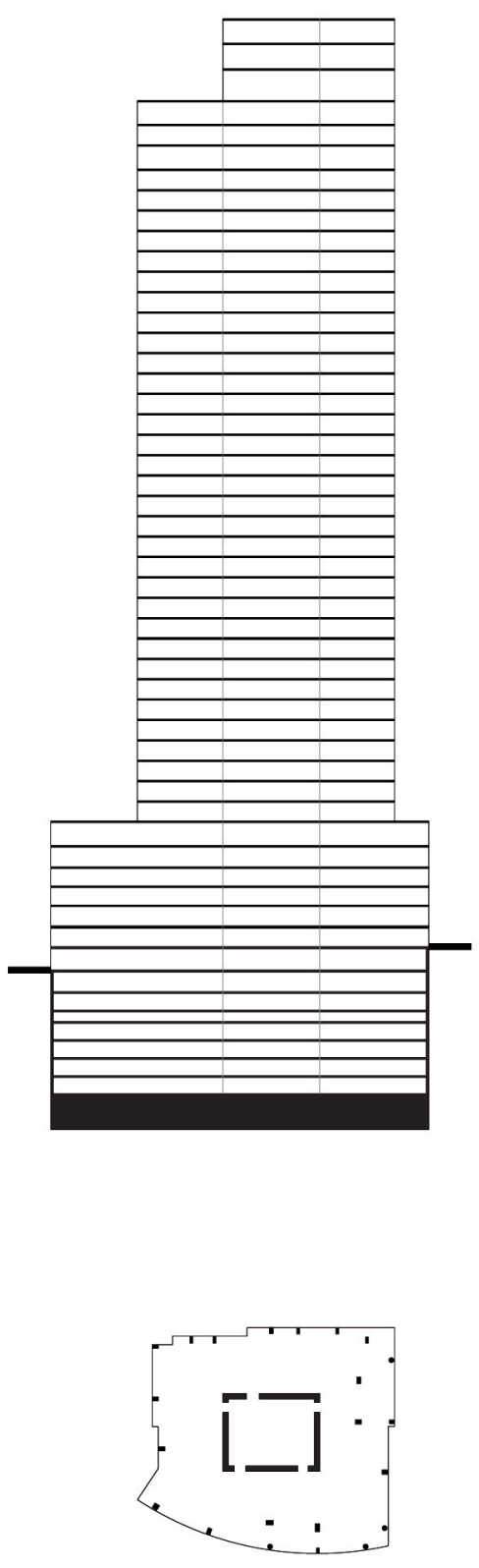

3: High Performance Lateral

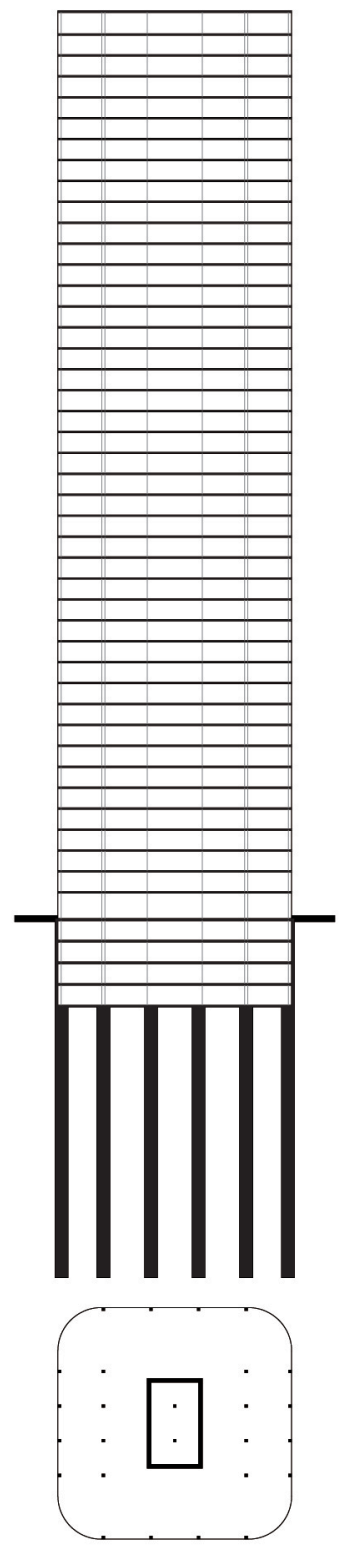

Figure 1: Three Case Study Building

Plans and Sections through the reduction of quantities and judicial specification of material, and case study three explored the environmental benefit of providing structural and non-structural systems that perform well in earthquakes. Case studies one and two both use process based LCA while case study three uses economic input output (EIO) LCA.

\section{BACKGROUND}

While many studies have used LCA to compare different buildings and building systems (e.g. Guggemos and Horvath, 2005 and Robertson, Lam and Cole, 2012), no published documentation of LCA studies completed to support certification by a green building rating system have been found. Different rating systems have integrated LCA into their metrics in slightly different ways. The IgCC (ICC, 2012) and LEED V4 (USGBC, 2015) both award 'points' for projects that demonstrate an improvement as compared to a baseline or 'reference' building. 
The Athena Institute has prepared a guide for conducting whole building LCAs (Athena, 2014) that outlines the specific differences of these programs and provides some guidance regarding application of whole building LCA. For this research we focused on attempting to achieve the LEED V4 criteria that requires a $10 \%$ reduction in a minimum of three impact categories (one of which must be global warming potential/CO2e emissions) and no more than a $5 \%$ increase in any of the other tracked impacts. The Living Building Challenge (ILFI, 2014) requires owners to purchase carbon offsets to account for the embodied carbon in the building: LCA is presumed to be the method to calculate the carbon impact.

\section{CASE STUDY 1: OFFICE BUILDING STRUCTURAL SYSTEM}

A 50,000sf, net-zero water and energy, office building in the Pacific Northwest was evaluated using different LCA tools and datasets. The plan and section of the building is shown in figure 1. For the LEED V4 test, the reduction in environmental impact by building the top four floors out of heavy timber wood was compared to a more conventional concrete structure. The goal of this study was to compare the LCA impacts for conventional concrete and wood as well as both schemes with high cement replacement in order to understand if switching to wood construction would be an adequate measure to demonstrate the $10 \%$ improvement required by LEED. For this study, the scope of the LCA included the structure (foundations, basement, gravity and lateral system for both the superstructure and penthouse structures), enclosure and interior partitions of the base building 'core'. The impacts related to tenant improvement, operational energy use, water use, MEP systems and site work were not tracked in this evaluation: this is a net zero energy and water building and these components are not required by LEED. The Athena Impact Estimator (Athena, 2014) was used to both estimate material quantities and determine the LCA impacts. A life span of 100 years was used for this study and the primary LCA stages (materials and construction: use, maintenance and replacement; and demolition and end of life) were included.

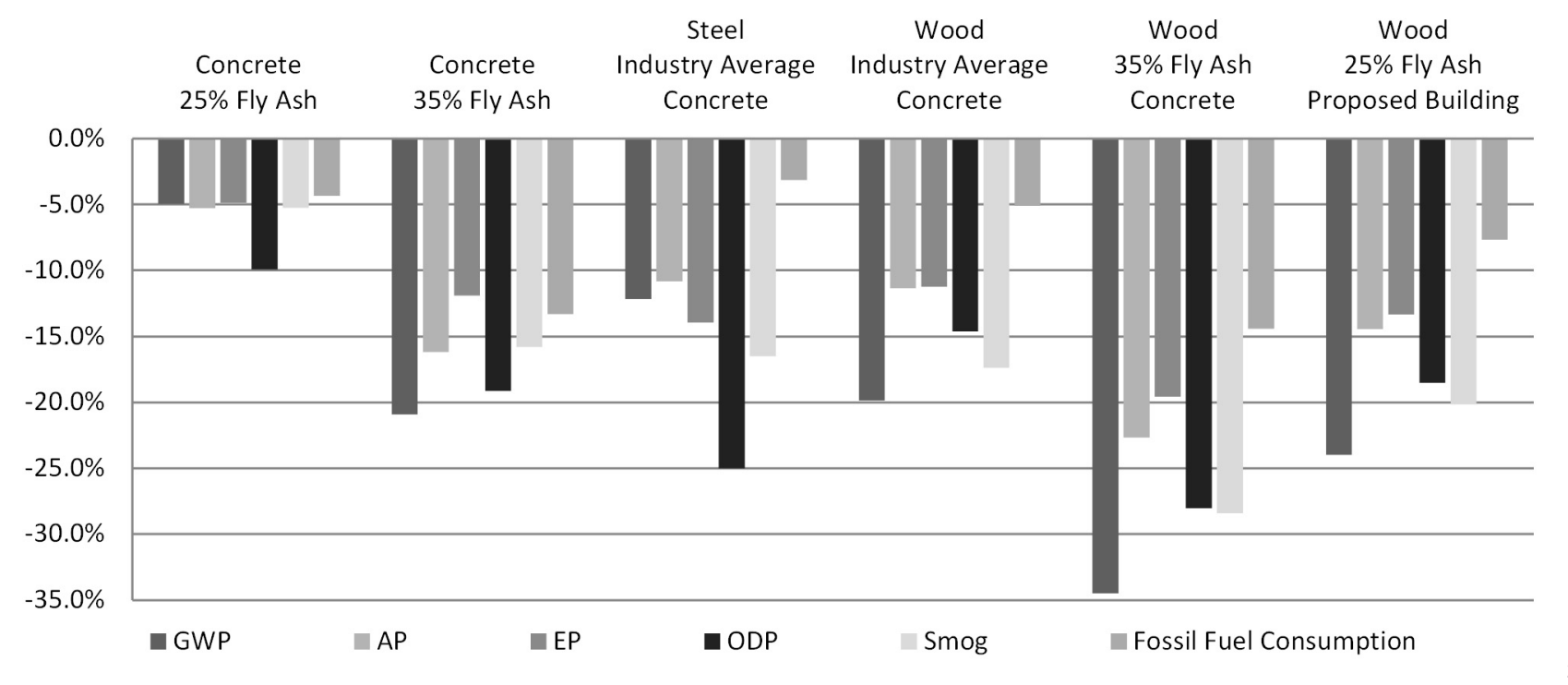

The LCA results, presented as a percent change from the baseline building (concrete slab using industry average concrete mixes) are summarized in figure 2 below. Of note, the $10 \%$ reduction could be met building the structure out of concrete (with high cement replacement), steel or wood. The building as proposed, has a nearly $25 \%$ reduction in Global Warming Potential. In this case the analysis was completed after the building was built in consultation with the owner's representative and with input from some of the sub

Figure 2: Comparing LCA results of structural options to baseline concrete building 
contractors. Additional LCA studies were completed that will be presented in future papers evaluating issues such as the impact of MEP/PV systems, the impact of long lifespan buildings and the durability of components and the variability resulting from different tools and users on the total embodied impacts of the building. The more comprehensive LCAs were also used to predict the total building carbon footprint for Living Building Challenge certification.

\section{CASE STUDY 2: OPTIMIZING MATERIAL SPECIFICATIONS}

This study was initiated by the general contractor (Sellen Construction) and structural engineer (Magnusson Klemencic Associates) who were interested in evaluating their current practices (which already included specifications that result in lower impact concrete and reinforcing steel) relative to the LEED V4 credit and to explore if conducting an LCA and setting targets can help to influence the final purchasing decisions. This project is currently finishing up the construction documents and selecting major subcontractors. The goal of this study is to target environmental improvements that would meet the LEED v4 Whole Building LCA credit through changes to specifications and detailing without impacting costs. The LCA scope included structure and enclosure and excluded interior partitions and construction.

During the design stage the research team recommended: using the regional industry average (RIA) concrete mixes (NRMCA, 2014) and reinforcing steel with impacts reduced from the industry global average data to represent local sourcing for the project baseline/reference building. The team identified three potential strategies to achieve the $10 \%$ reduction to the RIA reference baseline:

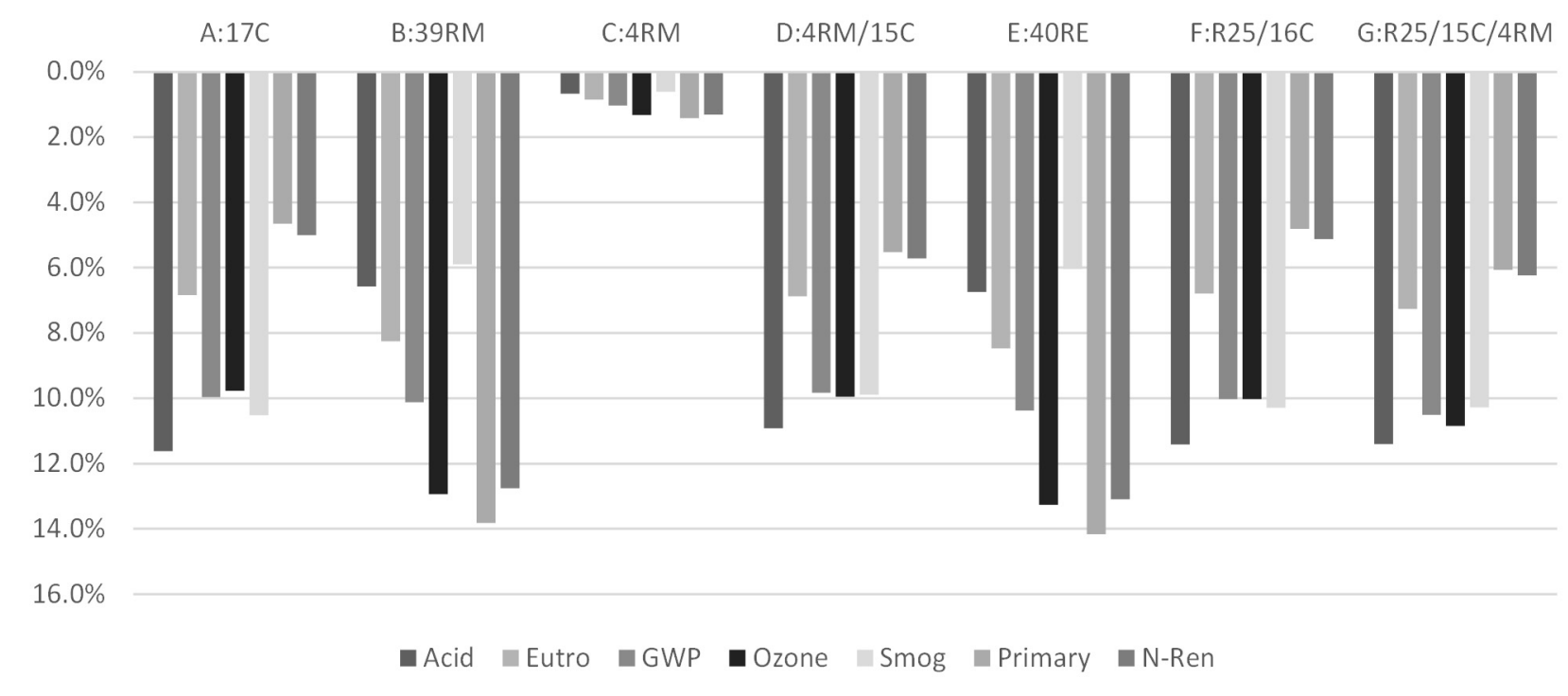

Figure 3: Reductions in total GHG emissions as compared to RIA for different structural strategies

1. Collaborate with concrete supplier, design and construction team to optimize mix designs to meet performance and constructability requirements at lowest environmental impact;

2. Reduce the quantities of reinforcing steel required through the use of terminators and couplers instead of splices and hooks and the use of high strength reinforcing steel; and

3. Sourcing reinforcing steel from the local Nucor plant, which is powered by the low carbon Seattle City Light electrical grid. 
The maximum benefit of each of the reduction options is noted in Figure 3:

A. $17 \%$ reduction in cement from RIA (17C);

B. $39 \%$ reduction in rebar materials quantities (39RM: not feasible);

C. $4 \%$ reduction in rebar quantities (4RM: practical, but not sufficient);

D. $5 \%$ reduction in rebar quantities (5RM) and $15 \%$ reduction in cement (15C);

E. $40 \%$ reduction in rebar electrical impacts $(40 \mathrm{E})$;

F. 25\% reduction in rebar energy for baseline (R25) plus 16\% reduction in cement;

G. $R 25,15 C$ and $4 \%$ reduction in rebar materials (4RM).

In order to demonstrate a $10 \%$ reduction from this baseline (as required to meet the LEED v4 credit), the team recommends working to optimize reduction of cement within the concrete and rebar quantities through alternate detailing practices. The design studies found that the $10 \%$ reduction can be met with modifications to structure (reducing cement use by $15-17 \%$, reducing steel quantities by $0-4 \%$ ) when compared to a reference building of the same size and configuration built using regional average concrete mixes and typical rebar detailing. Based upon this study the research team recommends: using the RIA concrete mix coupled with the R25 rebar energy reduction as project baseline; do not look for 'credit' for using locally sourced/low impact rebar as that is the current state of practice; and working with the design and construction team to optimize reductions of cement and rebar with options $F$ and $\mathrm{G}$ as potential targets.

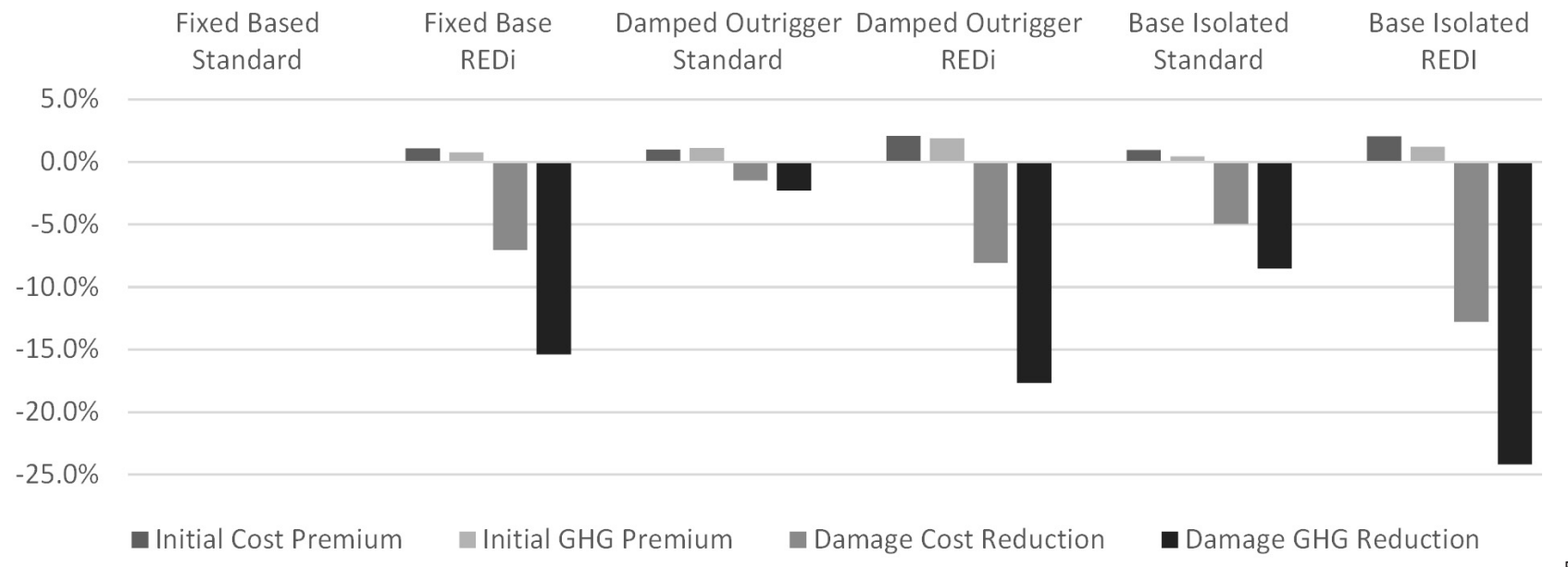

\section{CASE STUDY 3: HIGH PERFORMANCE LATERAL SYSTEM}

The San Francisco Office of Arup had previously conducted a study of the seismic performance of a prototype tall residential tower comparing different structural systems and performance targets (Almufti et. al, 2015) using probabilistic performance based seismic design. For this study we used Economic Input Output LCA to evaluate the cradle-to-gate impacts of initial construction and seismic damage (Simonen et. al, 2015). Based upon this study, the contribution of individual components to the total initial embodied impacts is represented in figure 4.

Three different lateral systems (fixed base/standard, damped outrigger and base isolated) were each evaluated for two different non-structural component performance metrics (standard detailing and enhanced detailing meeting Arup 'REDi' standards). Each of the

Figure 4: Initial Construction GHG Emission Breakdown (Total 90M kg cO2e)

Figure 5: Environmental 'cost' and 'benefit' for different performance levels as compared to baseline initial 


\section{ENDNOTES}

Almufti, I, Tipler, J., Merrifield, S., Carey, B., Willford, M. and G. Deierlein, (2015: under review).

"Performance and Cost Implications of Resiliencebased Earthquake Design for Tall Buildings in High Seismic Zones using the REDi' ${ }^{\text {TM }}$ Rating System," ASCE Special Issue on Resilience-Based Design of Structures and Infrastructure.

Athena Sustainable Materials Institute (Athena) (2014a) "Athena Impact Estimator for Buildings." Software. Available from www.athenasmi.org.

Athena (2014b) "Athena Guide to Whole-Building LCA in Green Building Programs", Athena Sustainable Materials Institute, accessed April 10, 2015 from http://www.athenasmi.org/wp-content/ uploads/2014/03/Athena_Guide_to_WholeBuilding_LCA_in_Green_Building_Programs_ March-2014.pdf.

US Environmental Protection Agency Science Advisory Board (1990). "Reducing Risk: Setting Priorities and Strategies for Environmental Protection." (Publication No. SAB-EC-90-021). Washington, DC. EPA

Guggemos, A. A., and Horvath, A. (2005). "Comparison of Environmental Effects of Steel- and ConcreteFramed Buildings." Journal of Infrastructure Systems, 11, 93-101.

International Organization for Standardization (ISO) (2006a) 14040:2006 Life Cycle Assessment-Principles and Framework. Geneva: ISO.

International Organization for Standardization (ISO). (2006b) 14044:2006 Environmental managementLife cycle assessment-Requirements and guidelines. Geneva: ISO.

International Code CouncillgCC (2012). International Green Construction Code. Country Club Hills, IL: International Code Council.

ILFI (2014) Living Building Challenge, International Living Futures Institute, accessed May 20, 2015 from https://living-future.org/sites/default/files/ reports/14-0828\%20v3.0\%20Doc\%20Reqs\%20 -FINAL\%2Bcover.pdf

FEMA (2012) Seismic Performance Assessment of Buildings: Volume 1 - Methodology (FEMA P-581), Federal Emergency Management Agency, accessed May 26, 2015 from http://www.fema. gov/media-library/assets/documents/90380.

National Institute of Standards and Technology (NIST) (2010). BEES [Software]. Available from http:// www.nist.gov/el/economics/BEESSoftware.cfm

NRMCA (2014) NRMCA Member Industry-Wide EPD for Ready Mixed Concrete, National Ready Mixed Concrete Association. Accessed April 8, 2015 from http://www.nrmca.org/sustainability/ EPDProgram/Downloads/NRMCA\%20EPD\%20 12.07.2014.pdf.

Robertson, A.B., Lam, F.C.F. \& Cole, R.J. (2012) "A Comparative Cradle-to-Gate Life Cycle Assessment of Mid-Rise Office Building Construction Alternatives: Laminated Timber or Reinforced Concrete," Buildings, 2012,2,245-270. schemes were analyzed using a probabilistic performance based design method developed by FEMA (FEMA, 2012) that estimates damage to both structural and non-structural components ( The damage for the typical design level earthquake (475 year return period) was evaluated and mean damage to components estimated and translated to environmental impact. The differences in environmental between the standard and highest performing scheme were nearly $25 \%$ as outlined in figure 5.

Although this study indicates that higher performing buildings can reduce the environmental impact of seismic damage by more than the $10 \%$ required by LEED, the results do not reflect the statistical likelihood of damage over a set time period. Although the FEMA methodology does provide guidance on how to achieve annualized damage impacts, conducting this added level of analysis is beyond the scope of most practitioners.

\section{DISCUSSION}

Life Cycle Assessment is being integrated into green building rating systems as a method of quantifying the environmental impact of material choices beyond the proxies of 'recycled content' and 'locally sourced' that may, but are not guaranteed to, reduce the impact of material choices. In each of these case studies academics and professionals collaborated to identify areas of potential improvement based upon their knowledge of building material manufacturing and production. In all cases the key opportunities for reducing the impact of building structures (switch to wood, use less cement, use less material overall and use energy efficient materials) selected by the design team were confirmed by the LCA. The rating systems reward LCA results that demonstrate improvement from a baseline building. Identified challenges include: defining the baseline building, equally weighting different impacts and the need for better LCA data on building materials and products.

Defining what is an appropriate baseline building is challenging, as it is not typical to have two fully developed designs to chose between. Selection of the baseline building will impact the opportunities and challenges in developing a final design that demonstrates significant improvement. For example, the more that is included in the baseline building (partitions, interior fittings etc.), the harder it will be to demonstrate a $10 \%$ reduction. For systems such as reinforced concrete, estimating the total quantities of reinforcing steel is a difficult and uncertain process for the design team to complete.

In one of our early iterations, one option had over $20 \%$ reduction in global warming potential and over $5 \%$ increase in eutrophication. This appears to have been generated by an error in the LCA dataset used by the whole building LCA tool (since corrected), however this highlighted an area of concern: if impact reductions in some categories are substantial, is it appropriate to negate the value of significant reductions of impact in multiple categories if one impact category shows increases of more than $5 \%$. There does not appear to be a scientific justification for the $10 / 5 \%$ thresholds and question their applicability. In particular, ozone depletion is no longer an area of significant concern as the emissions have been greatly reduced due to prescriptive requirements of the Montreal Protocol (UNEP, 2007). A $5 \%$ reduction of a VERY SMALL impact is not significant. We are exploring the use of different weighting schemes such as developed by NIST (NIST, 2010) and EPA (EPA, 1990) and believe weighted impact reduction may be a more appropriate measure for use when assessing whole building LCA credits in green rating systems.

Some building industry trade groups, such as the National Ready Mixed Concrete Association, have published LCA results for a range of products and that represent industry variation (NRMCA, 2014). Other industries are still developing data meaning that we must rely on a range of LCA data sources such as global average numbers. As noted in case study 3 , there are opportunities to reduce the impact of materials such as steel by selecting 
suppliers with energy efficient manufacturing processes and using lower environmental impact energy sources. At present, the opportunities to select between materials of the same type are limited and better product specific LCA data is needed.

\section{CONNECTIONS BETWEEN ACADEMIA AND INDUSTRY}

This research is founded upon connections between practice and the academy. In the process of developing these whole-building LCAs the academic and professional teams have been exploring the opportunities for integrating advanced environmental analysis into practice. The research conducted by graduate students has provided a platform for developing the knowledge and expertise within the student body to integrate LCA into academia and practice. Five students have integrated LCA into their thesis projects over the past two years. Projects such as these have been integrated into a seminar: Life Cycle Assessment for Architecture in which students develop projects in parallel with current whole-building LCA research. This term students are exploring the opportunities for tall wood structures in commercial construction and developing LCA studies to quantify the difference as compared to conventional construction methods.

\section{CONCLUSIONS}

Whole building LCA shows promise for evaluating and motivating lower impact buildings. Better LCA data, guidelines for conducting whole building LCAs and databases with a large quantity of reference buildings will be needed in order to accurately assess the actual improvement a specific building can provide compared to 'typical' conditions. However, we found the knowledge gained when conducting the LCAs and the questions asked when conducting the results to be of high value, increasing our understanding of both material specific and building system impacts. Therefore, we do not believe that the limitations of LCA should be used as an argument against its adoption rather through adoption, we expect to attain the better data, tools and benchmarks needed to improve its accuracy and effectiveness.

\section{ACKNOWLEDGEMENTS}

This research was funded by the University of Washington's Royalty Research Fund as well as the sponsors of the Carbon Leadership Forum's Platinum sponsors: Arup, Magnusson Kelemencic, Mithun, Russell Family Foundation and Webcor Builders. In addition the research could not be completed without the direct collaboration of industry collaborators: Ibrahim Almfuti, Don Davies, David Fields, Sean Merrifield, Alex Petusky, Jenni Tipler, and David Walsh as well as the University of Washington's graduate student researchers: David Fish, Lissa Goetz, Dhara Goradia and Kristen Strobel.
Simonen, K., Merrifield, S., Almfuti, I, Strobel, K., Tipler, J. (2015) "Integrating Environmental Impacts as another Measure of Earthquake Performance for Tall Buildings in High Seismic Zones," Proceedings of the ASCE Structural Engineers Institute 2015 Structures Congress, Portland, OR. Accessed April 29, 2015 from http://ascelibrary.org/doi/ pdf/10.1061/9780784479117.080.

United Nations Environment Program (UNEP) (2007). The Montreal Protocol. Retrieved from http:// ozone.unep.org/new_site/en/Treaties/treaties_ decisions-hb.php?sec_id=5

USGBC (2015) LEED v4 for Building Design and Construction, U.S. Green Building Council, accessed April, 8, 2015 from http://www. usgbc.org/sites/default/files/LEED\%20v4\%20 BDC_04.01.15_current.pdf. 